\title{
Water Absorption Behaviour and Its Effect on the Mechanical Properties of Flax Fibre Reinforced Bioepoxy Composites
}

\author{
E. Muñoz and J. A. García-Manrique \\ Departamento de Ingeniería Mecánica y Materiales, Universitat Politècnica de Valencia, Camino Vera s/n, 46022 Valencia, Spain \\ Correspondence should be addressed to E. Muñoz; emudom@mcm.upv.es
}

Received 27 February 2015; Accepted 12 August 2015

Academic Editor: Saiful Islam

Copyright ( 2015 E. Muñoz and J. A. García-Manrique. This is an open access article distributed under the Creative Commons Attribution License, which permits unrestricted use, distribution, and reproduction in any medium, provided the original work is properly cited.

\begin{abstract}
In the context of sustainable development, considerable interest is being shown in the use of natural fibres like as reinforcement in polymer composites and in the development of resins from renewable resources. This paper focuses on eco-friendly and sustainable green composites manufacturing using resin transfer moulding (RTM) process. Flax fibre reinforced bioepoxy composites at different weight fractions (40 and $55 \mathrm{wt} \%$ ) were prepared in order to study the effect of water absorption on their mechanical properties. Water absorption test was carried out by immersion specimens in water bath at room temperature for a time duration. The process of water absorption of these composites was found to approach Fickian diffusion behavior. Diffusion coefficients and maximum water uptake values were evaluated; the results showed that both increased with an increase in fibre content. Tensile and flexural properties of water immersed specimens were evaluated and compared to dry composite specimens. The results suggest that swelling of flax fibres due to water absorption can have positive effects on mechanical properties of the composite material. The results of this study showed that RTM process could be used to manufacture natural fibre reinforced composites with good mechanical properties even for potential applications in a humid environment.
\end{abstract}

\section{Introduction}

The environmental consciousness as well as the government legislation around the world has encouraged the academic and industrial researches to develop eco-friendly, sustainable, and biodegradable composite materials, thus often referred to as "green composites" [1]. Renewable and biodegradable materials as alternative to synthetic fibres and polymers derived from petroleum used in traditional fibre reinforced polymer composites $[2,3]$.

The interest in natural plant fibres (flax, hemp, jute, kenaf, etc.) [4-7] as reinforcement in polymer matrix has grown quickly in the last decade. Several advantages in comparison with synthetic fibres can explain it. They have low density, are annually renewable, and therefore are low in cost. Natural fibres are biodegradable, are crucial at the end of life of products, and have comparable specific strength and modulus as traditional glass fibres. Industries as automotive $[8,9]$ and construction [10] have started the manufacturing of products using natural fibre, to improve the environmental impact of the product due to the inexpensive price of natural reinforcements.

There are also some drawbacks in the use of natural fibre reinforced composites. Hydrophilic natural fibres are incompatible with hydrophobic thermosetting resins, and it is necessary to improve the adhesion between fibre and matrix, the use of chemical treatments $[11,12]$. Natural fibres as reinforcement have been limited by their susceptibility to water absorption, due to their chemical composition being rich in cellulose, hydrophilic in nature. Water absorption results in the swelling of the fibre that could reduce the mechanical and dimensional properties of the composites [13-15] as a result of the appearance of microcracks at fibre-matrix space.

There are three major mechanisms [13, 16-18] of water absorption in fibre reinforced polymer composites: diffusion, capillary, and transport of water molecules, respectively. Diffusion mechanism occurs inside the microgaps between the chains of polymers. Capillary transport mechanism occurs in the gaps at fibre-matrix interface space, if during manufacturing process the impregnation of the reinforcement with 
TABLE 1: Structural composition of flax fibre.

\begin{tabular}{lccccc}
\hline Cellulose (wt\%) & Hemicellulose (wt\%) & Lignin (wt\%) & Pectins (wt\%) & $\begin{array}{c}\text { Microfibril angle } \\
(\text { degree })\end{array}$ & $\begin{array}{c}\text { Moisture content } \\
(w t \%)\end{array}$ \\
\hline 71 & $18.6-20.6$ & 2.2 & 2.3 & $6-7$ & 10 \\
\hline
\end{tabular}

TABLE 2: Comparison of the properties of flax and glass fibre.

\begin{tabular}{lcccc}
\hline Fibre & Density $\left(\mathrm{g} / \mathrm{cm}^{3}\right)$ & Elongation at break $(\%)$ & Tensile strength $(\mathrm{MPa})$ & Tensile modulus $(\mathrm{GPa})$ \\
\hline Flax & 1.5 & $2.7-3.2$ & $500-900$ & $50-70$ \\
E-glass & 2.5 & 2.5 & $2000-3500$ & 70 \\
\hline
\end{tabular}

the matrix has been incomplete. In natural fibre composites, the transport of water molecules through the microcracks that can appear in the matrix is especially important, as a result of the fibre swelling. According to this mechanisms, there are three cases of diffusion behavior $[19,20]$ known as Fickian diffusion model, anomalous or non-Fickian, and an intermediate case between Fickian and non-Fickian.

The manufacturing of natural fibre composites includes the use of thermoplastics polymer such us polypropylene, polyethylene, and polyamides combined with the natural fibre random mat or short fibres through injection molding, compounding, extrusion, or thermoforming processes. Automotive industry is a clear example, where their use for nonstructural components can be found [21] as interior glove box and door panels or exterior floor panels. In the case of natural fibre reinforced thermosetting matrix composite, the most used manufacturing process in the literature has been hand lay-up and liquid compression molding, for nonwoven or random mats due to the low costs associated with these techniques. Nowadays, research and industrial applications focus on the aligned natural fibre composites applications using continuous natural textile reinforcements like unidirectional (UD), woven, and noncrimp fabrics, at this time, commercially available. The potential of use of natural fibre fabrics will improve significantly the composite properties for engineering applications or high performance natural fibre composites. Additionally, in combination of thermosetting polymer matrices, it will allow the use of well-established manufacturing techniques as liquid composite moulding (LCM) processes, as resin transfer moulding (RTM) or vacuum infusion. Only a few studies [22] have been focused on the processing of natural fiber composites by LCM processes. This study will focus on the manufacture of flax fibre woven fabric reinforced bioepoxy composites by RTM process and the evaluation of their mechanical properties. In order to study the potential of use of these composites in outdoor applications or humid environmental conditions, the water absorption behavior of flax fibre bioepoxy composites at room temperature and various weight fractions of fibre has been investigated as well as its effect on the mechanical properties (tensile and flexural).

\section{Materials and Methods}

2.1. Materials. A $200 \mathrm{~g} / \mathrm{m}^{2}$ flax fibre balanced woven fabric $\left(0^{\circ} / 90^{\circ}\right)$, supplied by Lineo, Belgium, has been used as textile reinforcement for the manufacturing of bioepoxy matrix composites. Table 1 shows the chemical composition of flax fibres [12]. Table 2 [1] shows the properties (mechanical and physical) of flax fibre compared to glass fibre.

A commercially available biobased epoxy resin, Super Sap CLR Epoxy supplied by Entropy Resins, USA, was used as polymer matrix in this work. According to technical data sheet of the manufacturer, Super Sap CLR Epoxy is a modified liquid epoxy resin. As opposed to traditional epoxies that are composed primarily of petroleum-based materials, this biobased epoxy resin contains in its chemical formulation (trade secret) biorenewable materials sourced as coproducts or waste of other industrial processes such as wood pulp (epoxidized pine oils) and biofuels production (nonfood grade vegetable oils). The biocontent by mass value is between $30.8 \%$ and $45.2 \%$ and uses biocarbon content number (ASTM D6866) and molecular structure to calculate total percentage of mass derived from biosources.

Super Sap INF Hardener is the curing agent employed. According to technical and material safety data sheets supplied by the manufacturer, it is a cycloaliphatic polyamine. Resin and hardener were mixed to a weight ratio of $100: 33$. The epoxy system (resin-hardener) has a biocontent by mass between $21 \%$ and $30 \%$.

2.2. Manufacturing Process. Liquid composite moulding process (LCM) consists of the manufacture of composites from polymer matrix by the impregnation of a dry fibrous fabric inside of an enclosed mold with a low viscosity resin. The resin is injected into the mold by the pressure difference between the resin inlet and the air outlet. The pressure difference can be either positive as resin transfer moulding (RTM) process shown in Figure 1 or negative as vacuum injection process. The process begins with the injection of the resin into the mold and ends when the resin completes the chemical reaction of curing and the part is ejected. The polymerization reaction is highly exothermic and its duration is widely variable and depends on the type of resin, inhibitor used, mold temperature, and especially the ratio of resin to inhibitor. The injection pressure must be low enough to give the proper fabric impregnation and to ensure that it does not become displaced by resin flow inside the mold. This pressure varies between 0.5 bar in vacuum injection and 3 bar for pressure injection. 


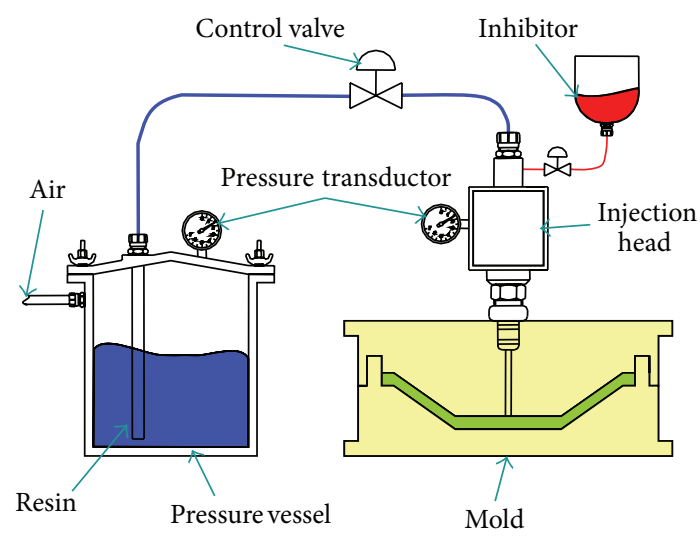

FIGURE 1: RTM manufacturing process under constant injection pressure.

The principal advantages of these LCM processes compared to the traditional hand lay-up are

(i) elimination of manual impregnation, avoiding risks to workers from inhalation of toxic styrene vapour present in thermosetting resins,

(ii) both sides of the component having a good surface quality due to the closed mold,

(iii) preventing induced anisotropy of the fabric, since it is preplaced into place before impregnation,

(iv) increasing production rate due to the automation of some phases of the process.

In this study, resin transfer moulding process was used to manufacture $400 \times 260 \mathrm{~mm}$ green composite laminates. To achieve different fibre volume fractions 0.4 and 0.55 , a different number of layers of flax fabric were placed in the rigid mold, 6 and 8 layers, respectively. A metallic frame with the thickness $(3 \mathrm{~mm})$ of the composite laminate was placed between top and bottom aluminum mold. The mold was closed and resin injection was performed at a pressure of $1 \mathrm{bar}$, with vacuum assistance. The laminates were cured for $24 \mathrm{~h}$ at room temperature. Laminates were removed from the mold and finally postcured at $50^{\circ} \mathrm{C}$ for 2 hours in an oven. Figure 2 shows the flax fibre fabric reinforcement placed in the mold before resin injection and manufactured composite laminate.

2.3. Water Absorption Tests. To study the behaviour of water absorption of the flax fibre reinforced bioepoxy composites, water absorption tests were carried out according to UNEEN ISO 62:2008 [23]. Composite samples were immersed in a water bath (deionized, $23^{\circ} \mathrm{C}$ ) during a time period until the saturation was reached. Five specimens from each fiber volume fraction with dimensions $250 \mathrm{~mm} \times 25 \mathrm{~mm} \times 3 \mathrm{~mm}$ (tensile samples) and $90 \mathrm{~mm} \times 15 \mathrm{~mm} \times 3 \mathrm{~mm}$ (flexural samples) were cut from composite panels. An oven was used, firstly to dry all the samples at $50^{\circ} \mathrm{C}$ during $24 \mathrm{~h}$, and then they were cooled to room temperature. The drying process was repeated, until the weight of the specimens was constant (mass $m 1$ ). After $24 \mathrm{~h}$, the samples were removed from the water and were weighed (mass $m 2$ ) using a digital scale

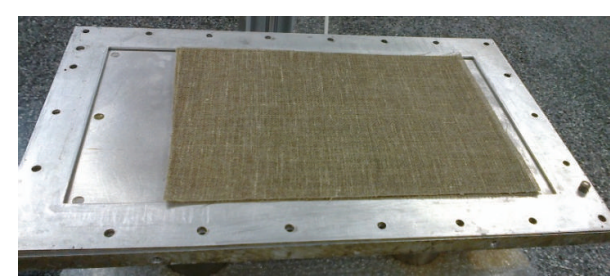

(a)

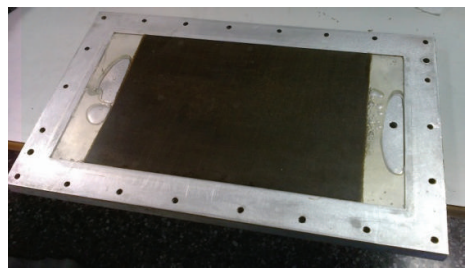

(b)

Figure 2: Flax fibre fabric and flax fibre reinforced composite.

immediately after they were dried with dry cloth. This process was repeated, to weigh the specimens regularly (mass $m t$ ) over 32 days of water immersion.

At different periods of time, the percentage of weight gain was calculated and it was plotted versus square root of water immersion time. As a result, the average value was reported. The difference of weight between the sample in dry conditions and that after water immersion at time $t$ was obtained as follows:

$$
M_{t}(\%)=\frac{m t-m 1}{m 1} * 100
$$

where $m t$ is the weight of the sample at time $t$ during water immersion and $m 1$ is the weight of the dry sample at initial time.

According to the model developed [23] in order to describe the water absorption of one material following Fickian behavior or Fick's diffusion laws, the moisture content $c(t)$ as function of the time can be expressed as function of diffusion coefficient $(D)$, the weight moisture $\left(c_{s}\right)$ in the saturated material, and their thickness $(d)$ as the following equation:

$$
c(t)=c_{S}-c_{S} \frac{8}{\pi^{2}} \sum_{k=1}^{20} \frac{1}{(2 k-1)^{2}} \exp \left[-\frac{(2 k-1)^{2} D \pi^{2}}{d^{2}} t\right] .
$$

Therefore, if water absorption behavior follows Fickian diffusion pattern, it can be described with the following formula $[13,14,24]$ :

$$
\frac{M_{t}}{M_{\infty}}=4 \sqrt{\frac{D t}{\pi h^{2}}}
$$

At initial absorption stage, water absorption $\left(M_{t}\right)$ at time $t$ increases linearly with $\sqrt{t}$ and $M_{\infty}$ denotes the quantity after infinite time or maximum weight gain when material approaches at saturation point. The average diffusion coefficient $(D)$ of the composites was calculated by 
TABLE 3: Water absorption and diffusion coefficients of flax fiber composites after the immersion in water.

\begin{tabular}{lccc}
\hline Fibre volume (\%) & Saturation water absorption $M_{s}(\%)$ & Slope $(k)$ & Diffusion coefficient, $D, \times 10^{-6}\left(\mathrm{~mm}^{2} / \mathrm{s}\right)$ \\
\hline 40 (6-layer flax) & & & 1.63 \\
Tensile specimen & 6.23 & $6 \times 10^{-5}$ & 1.47 \\
Flexural specimen & 6.56 & $6 \times 10^{-5}$ & 2.32 \\
55 (8-layer flax) & & & 1.85 \\
Tensile specimen & 8.71 & $1 \times 10^{-4}$ & $1 \times 10^{-4}$ \\
Flexural specimen & 9.76 & & \\
\hline
\end{tabular}

the measurements of weight gain and the initial slope of the weight gain curves versus square root of time, as follows:

$$
D=\pi\left(\frac{k h}{4 M_{\infty}}\right)^{2},
$$

where $h$ is the thickness of the specimens, $M_{\infty}$ is the maximum weight gain, and $k$ is slope of the initial plot $M(t)$ versus $\sqrt{t}$.

\subsection{Mechanical Tests}

2.4.1. Tensile Test. To evaluate the tensile properties of the dry composite samples and of the samples with water absorption, tensile tests were conducted according to UNE-EN ISO 5274:1997 [25]. An Instron 5960 universal testing machine with a load cell of $30 \mathrm{kN}$ was used with a crosshead speed $2 \mathrm{~mm} / \mathrm{min}$. Ten rectangular specimens of each fibre content were cut from the manufactured composite laminates. Five specimens $(250 \mathrm{~mm} \times 25 \mathrm{~mm} \times 3 \mathrm{~mm})$ were tested for each case, dry or wet samples. Stress-strain curves were obtained and the average values for tensile strength, tensile strain at tensile strength, and tensile modulus were reported as a result.

2.4.2. Flexural Test. Flexural tests were conducted according to UNE-EN ISO 14125:1999 [26] to determine the flexural properties of the flax composites with and without water absorption. Universal testing machine (Instron 5960, $30 \mathrm{kN}$ load cell) was used to carry out three-point bending tests, with a span of $60 \mathrm{~mm}$ between supports and a crosshead speed applied of $2 \mathrm{~mm} / \mathrm{min}$. Ten rectangular specimens of each fibre content were cut from the manufactured composite laminates. Five specimens $(90 \mathrm{~mm} \times 15 \mathrm{~mm} \times 3 \mathrm{~mm})$ were tested for each case, dry or wet samples; the average values for flexural strength, strain, and modulus were reported as a result.

2.4.3. Morphological Analysis: SEM. The tensile fracture surfaces of dry and water immersed composite specimens were observed with (SEM) JEOL-JSM 6300, $20 \mathrm{kV}$ scanning electron microscope. To make the samples conductive, it is necessary to vacuum-coat them with a thin film of gold.

\section{Results and Discussion}

3.1. Water Absorption Behavior. The water absorption of the composite samples was calculated with (1). The weight gain (\%) as a function of square root of time for the tensile and flexural specimens after water immersion at room temperature and different content of fibre is shown in Figure 3.

For the samples with 6 layers of flax $(0.40$ fibre volume fraction) after $768 \mathrm{~h}$ of water immersion, the maximum percentage weight gain is $6.23 \%$ for tensile samples, and $6.56 \%$ for flexural samples. This slight difference for the same fibre volume fraction can be explained due to the variability of the natural constituents of the fibre. Plant fibre reinforcements can exhibit significant inconsistency in their properties. Chemical composition, dimensions, and surface density of the fibre can be affected due to the conditions of the growing $[27,28]$.

In the same way, maximum percentage weight gain for the specimens with 8 layers of flax ( 0.55 fibre volume fraction) immersed for $768 \mathrm{~h}$ is $8.71 \%$ for tensile samples, and $9.76 \%$ for flexural samples.

As can be seen, for all the samples, the process of water absorption is at the beginning linear. After it slows and finally after extended immersion time, the samples approaches to the saturation stage. Therefore, for all the samples, its behavior of water absorption can be modeled as diffusion process type Fickian.

As the fibre volume fraction increases, for all samples, the initial rate of the process and the maximum water absorption increases. This phenomenon can be explained [29] by the hydrophilic nature of vegetable fibres, as flax fibres, due to the fact that they are cellulose fibres. If the vegetal fibres are exposed to a process of water absorption, the fibre swells. Besides, as a result of the swelling, microcracks can appear in a brittle matrix as epoxy resin and, in turn, can lead to largest transport of water through the fiber matrix interface.

Table 3 shows saturation water absorption values and the diffusion coefficients calculated for water immersed specimens at room temperature $\left(23^{\circ} \mathrm{C}\right)$. The results show that the diffusion coefficient and maximum water content values increase as the fibre content increases. Samples with a higher fibre content have a greater diffusion coefficient, due to the fact that absorption of water is higher, as a result of a higher content of cellulose. The formation of microcracks at the interface region, induced by fibre swelling, can increase the diffusion transport of water via them. Furthermore a capillarity mechanism becomes active; water molecules flow through the interface of fibre and matrix, leading to a greater diffusivity [30]. The difference of diffusion coefficient values for the same fibre volume fraction composites can be explained again, due to the scattering of natural constituents of the fibre, and it can be assumed. 


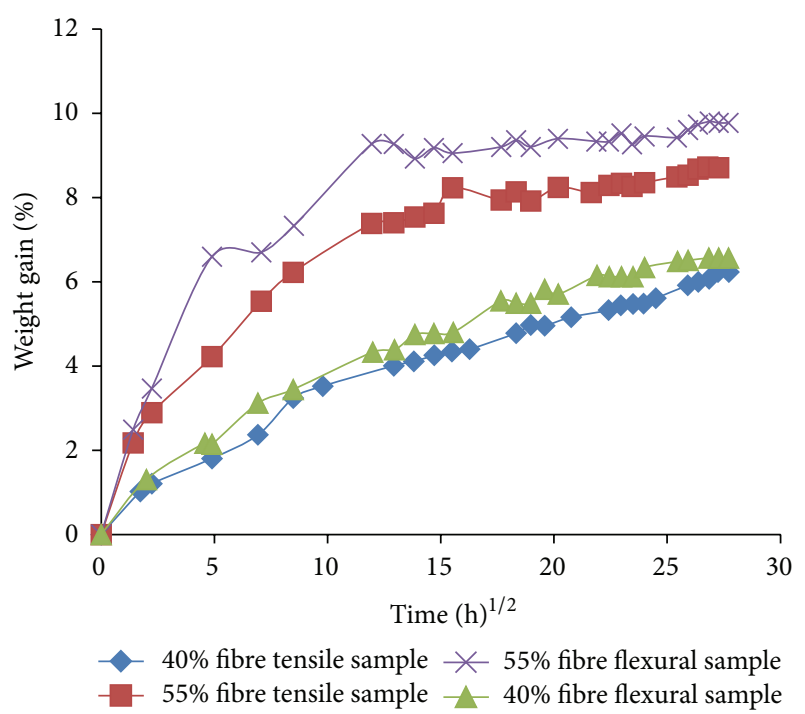

FIGURE 3: Curves of water absorption for the different flax composite samples.

\subsection{Effect of Water Absorption on the Mechanical Properties}

3.2.1. Tensile Properties. Figures 4 and 5 show the results of the tensile strength and strain versus fibre volume, respectively, for the samples without (dry) and with water absorption $(768 \mathrm{~h}$ water immersed). For the dry samples, their tensile strength increases with the increase of fibre content. This enhancement in flax reinforced composite strength is the result of higher loads supported by the fibres, due to the higher load transfer from the matrix to them. As it can be seen, the water immersed samples have a higher tensile strength compared to tensile strength of the dry samples. It may be attributed to the swelling of the fibres as a result of the water absorption in high quantities. The gaps between the fibre and the matrix that can appear during manufacturing process due to a poor impregnation or the shrinkage of the resin cure could be filled up and therefore can eventually lead to an improvement of the mechanical properties, in this study, an increase of the tensile strength.

This effect was reported by Karmaker et al. [31]; it was studied if the fibre swelling by the water absorption could fill up the gaps between jute fibers and polypropylene matrix, as a result of the thermal shrinkage of the matrix melt. To fill up these gaps, can result, during the fracture stage, in a higher shear strength between the fibers and matrix. Dhakal et al. [13] found that the ultimate tensile stress of hemp reinforced unsaturated polyester composites with a fibre volume fraction of 0.26 (5-layer nonwoven hemp fibre) after a period of water immersion was higher compared to the same samples without water absorption. It was also attributed to the filling up of the gaps between fibre and the matrix, as a result of the swelling of the fibre.

The microcracks that can appear in a brittle matrix (as an epoxy resin) due to the fibre swelling can lead to a weak bonding between the fibres and the matrix and in turn can lead to composite failure. However in this study, this effect

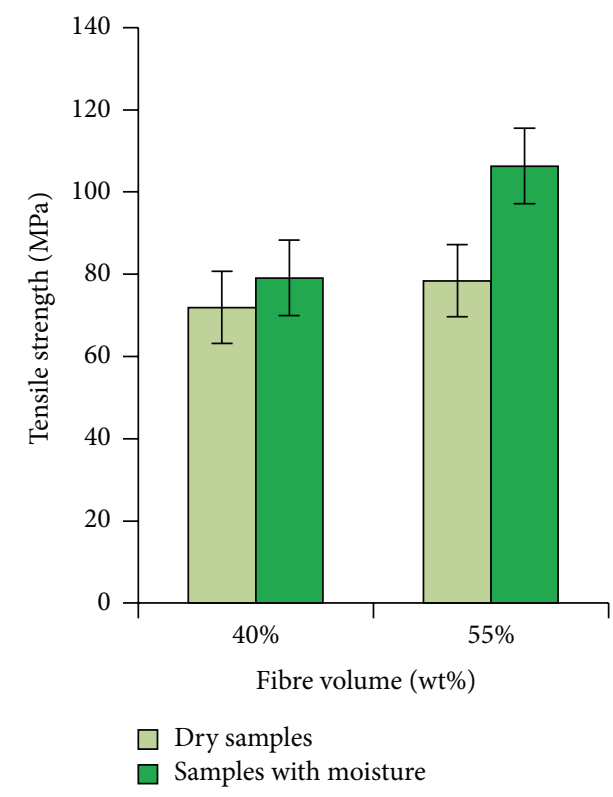

FIgURE 4: Tensile strength versus fibre volume.

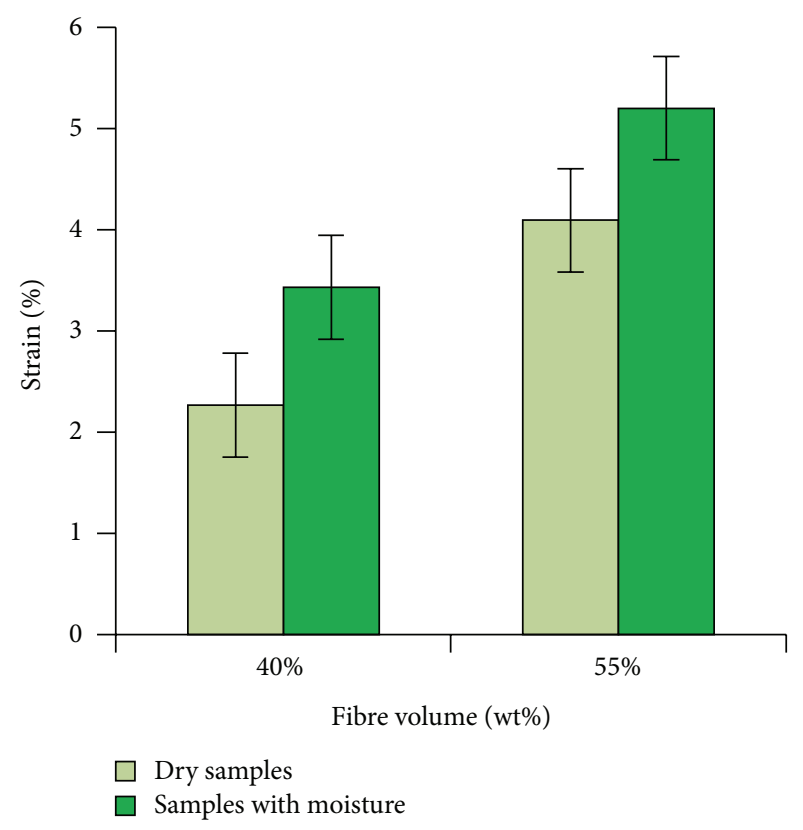

Figure 5: Tensile strain versus fibre volume.

seems to have less influence. The resin used as matrix is an epoxy resin modified with the addition of epoxidized pine oil. Epoxidized vegetables oils (EVO) can form elastomeric networks [32] as a result of its polymerization with the suitable curing agent. EVO can be added into conventional synthetic epoxy resin to be used as natural plasticizer or toughening additive [33-35] to reduce its rigid and brittle behavior.

After immersion in water, Figure 4 shows that the tensile strength of the samples reinforced with 6 flax layers increases $10 \%$, and the same behavior is observed for the samples with 8 layers, where the tensile strength increases $35 \%$. 


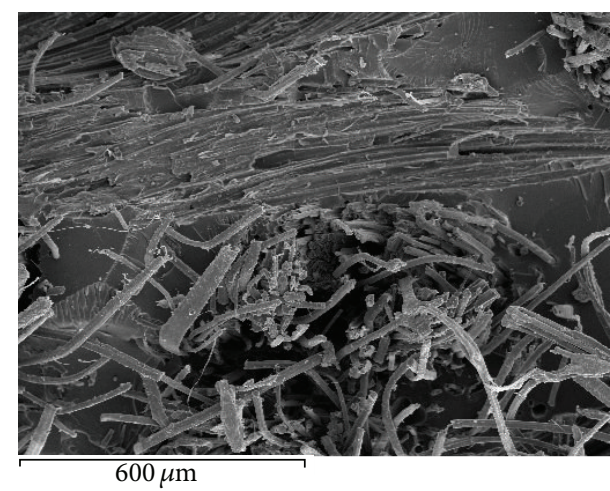

(a)

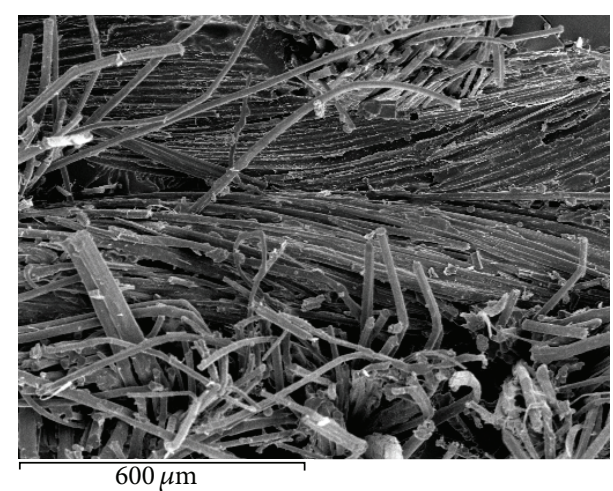

(b)

FIGURE 6: SEM tensile fracture images of dry composite samples with fibre content (a) $40 \mathrm{wt} \%$, (b) $55 \mathrm{wt} \%$.

As can be seen in Figure 5, for all the samples with water absorption, the tensile strain values increase compared to the values of the dry samples. For $40 \mathrm{wt} \%$ flax reinforced samples, the strain increases $51 \%$ and $27 \%$ for $55 \mathrm{wt} \%$ flax samples. It can be due to the water absorption causing the plasticization of flax composite samples. As it was reported for similar composites [36, 37], the water absorbed by the composite causes mainly the swelling of natural reinforcement, but also the plasticization of both the resin and the natural fibres.

Dhakal et al. [13] have reported similar results for hemp fibre reinforced unsaturated polyester composites, where it was found that the failure tensile strain values for samples with different fibre volume fractions increase after water absorption process, compared to the values obtained before the immersion in water.

The effect of water absorption on mechanical properties of the composite can be understood if its effect on their constituents, the matrix, the fibre, and the fibre-matrix interface region is studied. The SEM micrographs of the tensile fracture surface of composite specimens support these results.

3.2.2. SEM Micrograph of Tensile Fracture Surface. Figures 6(a) and 6(b) show the SEM images of the tensile fracture surface of flax reinforced epoxy composites without water absorption (dry samples) with fibre contents of 40 and $55 \mathrm{wt} \%$, respectively. Fibre breakage, matrix fracture, fibre debonding, and fibre pull-outs can be observed after tensile test for both composites. It is clearly seen in the images, the fibre content on the fracture surface. The composite with lower fibre content ( $40 \mathrm{wt} \%$ ) shows an increase in matrix rich regions compared to the composite with higher fiber content (55 wt\%). Lower fibre content will lead to low mechanical properties, due to the fact that there are less fibres that can support the transferred load from the matrix.

For all water immersed samples in Figure 4, tensile strength increased compared to the dry specimens. Water caused the swelling of the fibres, and it was attributed to the filling up of the gaps between the fibre and the matrix. This effect could lead specifically to an increase in the mechanical properties of the composite. Gaps formed during the manufacturing process due to a poor impregnation of the reinforcement or to thermal shrinkage of the resin cure. With the swelling of the fibre, the empty space fibre-resin can disappear, and the fibres exert pressure on the matrix, which results in a perfect adhesion. The SEM image in Figures 7 (a) and 7 (b) shows matrix region for $40 \mathrm{wt} \%$ fibre reinforced sample in dry conditions and for $40 \mathrm{wt} \%$ water immersed sample, respectively. This SEM image shows an enhanced or stronger bonding between the fibers and the matrix in wet conditions compared to the other sample in dry conditions, which results in a more efficient transfer of stress along the fibre-matrix interface before composite failure. Therefore in this case, it results in an increase of the composite strength after water immersion. Similar effect was also observed in dry and water immersed samples with $55 \mathrm{wt} \%$ fibre content.

In addition, the fracture surface of dry samples after tensile test showed flax fibre breakage in a more brittle manner, compared to fracture surface of water immersed samples, as it can be observed in Figures 8(a) and 8(b) for $40 \mathrm{wt} \%$ fiber content composite sample. In wet conditions, it is seen that fibre surface is rougher and some split into thinners fibrils occurs, caused by water absorption. The plasticization of flax composite samples caused by water absorption was found to increase the tensile strain values of all samples after water immersion compared to dry samples. The matrix rich zones seem to show the same behavior before and after the water absorption, and besides, they are not perceptible microcranks in the matrix around the fibre, in the case of the water immersed samples, maybe due to the higher flexibility of the epoxy resin used. Similar fracture surface was also observed in dry and water immersed samples with $55 \mathrm{wt} \%$ fibre content. Note that wet samples probably lost part of the water uptake during the sample preparation for SEM.

3.2.3. Flexural Properties. Figures 9 and 10 show the results of the flexural strength and strain versus fibre volume, respectively, for the samples without (dry) and with water absorption (768 $\mathrm{h}$ water immersed).

For the dry samples flexural strength increased as fibre content increases. This enhancement of the composites flexural strength is due to the increase of transferred load to the fibres, because of the higher adhesion at interface zone 


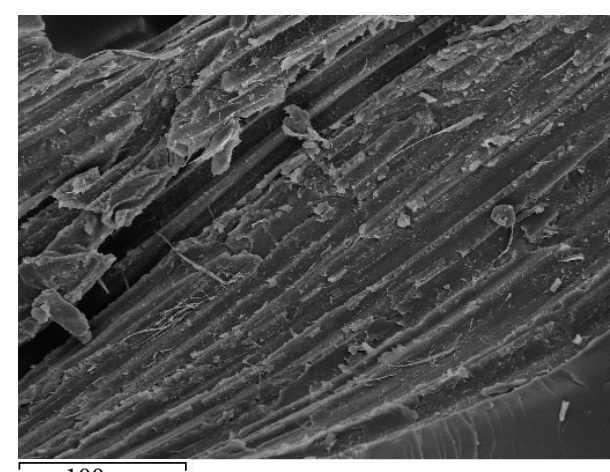

$100 \mu \mathrm{m}$

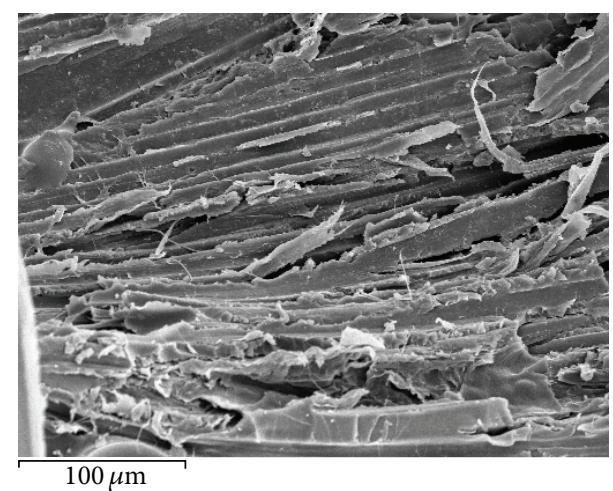

(b)

FiguRE 7: SEM images of fibre-matrix adhesion of $40 \mathrm{wt} \%$ fibre content samples (a) in dry conditions and (b) after water immersion.

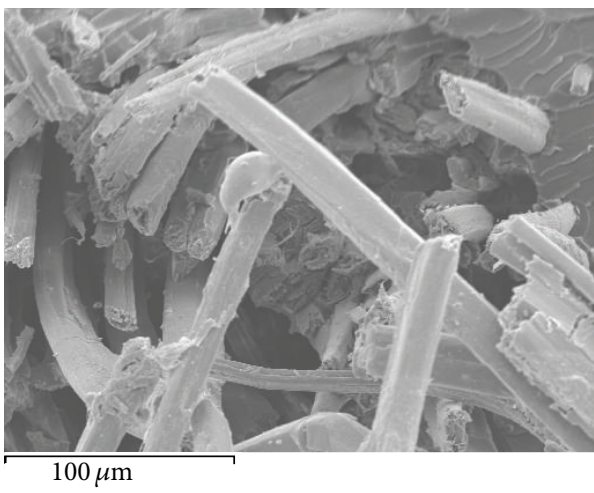

(a)

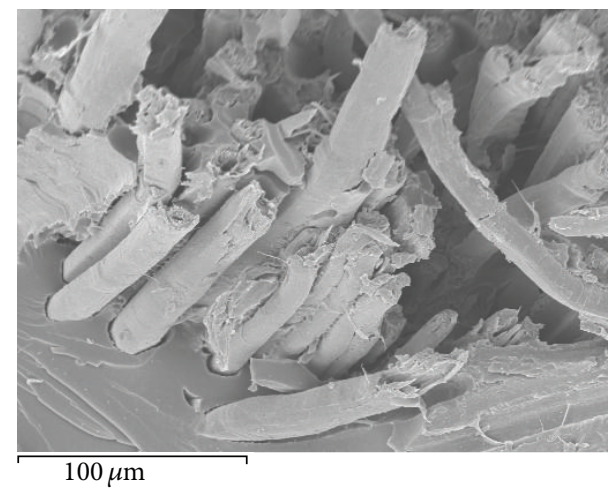

(b)

FIGURE 8: SEM images of fracture surface and fibre breakage: (a) dry composite sample, (b) water immersed composite sample.

(fibre-matrix) region, and due to the property of cellulose fibres as flax fibre to support bending loads [38].

The flexural failure mode for both dry and water immersed samples occurs in the same way. The specimen fails suddenly in a linear mode at the bottom surface of the specimen. As a result of the fact that there is no interlaminar failure at the thickness of the specimen, shear failure mode does not occur.

As the fibre volume fraction increases (Figure 9), flexural strength for water immersed samples decreases. This decrease can be attributed to the increase in the percentage of water absorption that can lead to the formation of higher number of microcracks as a result of fibre swelling which in turn weaken fibre-matrix interface region when bending loads are applied.

In this study, to observe that the 6 flax layers' samples (40 wt $\%$ fiber content) have a higher flexural strength after water immersion, compared to dry samples, an increase of $25.5 \%$ was found. It could be due to swelling of the fibres, previously mentioned, that can fill up the gaps between fibre and matrix, increasing the bonding between them, which results in an increase of mechanical properties. However for $55 \mathrm{wt} \%$ specimens (8-layer flax), flexural strength of the water immersed samples decreases by $20 \%$ compared to dry samples.
An increase of water absorption quantity (Figure 3) as occurs in the $55 \mathrm{wt} \%$ fibre flexural specimens compared to $40 \mathrm{wt} \%$ fibre specimens decreases their flexural strength. It may be caused by the weak interfacial adhesion between fibre and matrix [15], as a result of the appearance of hydrogen chemical bonds between the cellulose fibre (flax fibres) and the water molecules [37].

Flexural strain of the samples with water absorption, as can be seen in Figure 10, increased compared to dry samples. After water immersion, once the loss of cellulose has taken place [39] natural fibre reinforced composites approach to be ductile. The molecules of water behave as plasticizer elements, leading to an increase of the maximum strain of the composite after water absorption [40].

3.2.4. Effect of Water Absorption on Tensile and Flexural Modulus. Table 4 lists the obtained values of tensile and flexural modulus of the samples without (dry) and with water absorption (wet, $768 \mathrm{~h}$ water immersed) after tensile and flexural tests. A change was found in the values of modulus as a result of the water absorption. Tensile modulus decreased for all samples after water immersion compared to dry specimens. Tensile modulus decreases $28 \%$ and $21 \%$ for 0.4 and 0.55 fiber volume fraction samples, respectively. 
TABLE 4: Tensile and flexural modulus values of flax composite.

\begin{tabular}{lcccrr}
\hline \multirow{2}{*}{ Composite specimens } & \multirow{2}{*}{ Fibre volume (wt\%) } & \multicolumn{2}{c}{ Tensile modulus (GPa) } & \multicolumn{2}{c}{ Flexural modulus (GPa) } \\
& & Dry & Wet & Dry & Wet \\
\hline 6-layer flax & 40 & 7.24 & 5.16 & 7.77 & 8.67 \\
8-layer flax & 55 & 7.67 & 6.06 & 6.96 & 4.82 \\
\hline
\end{tabular}

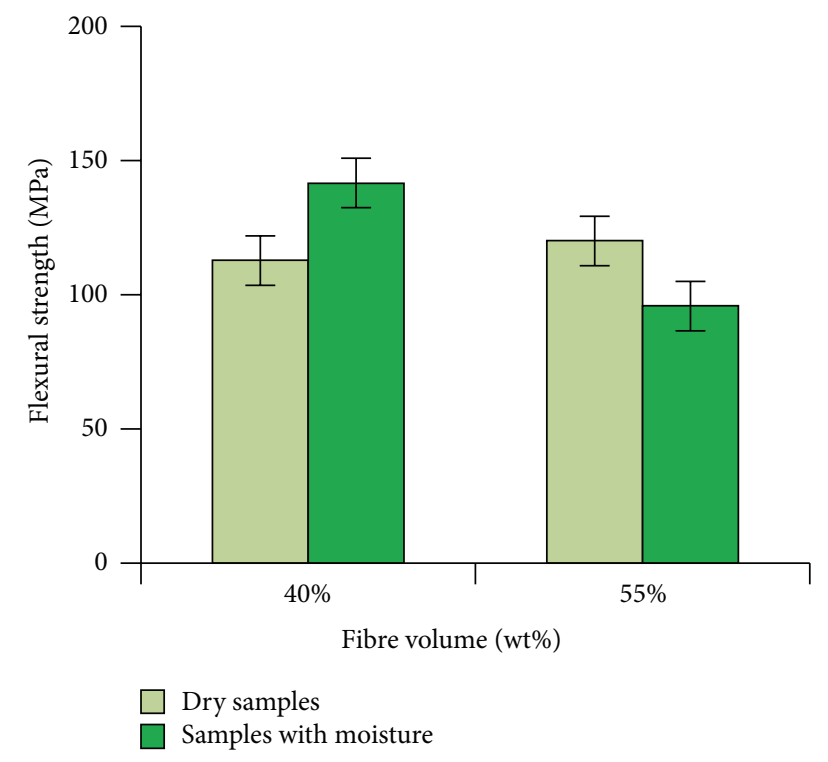

Figure 9: Flexural strength versus fibre volume.

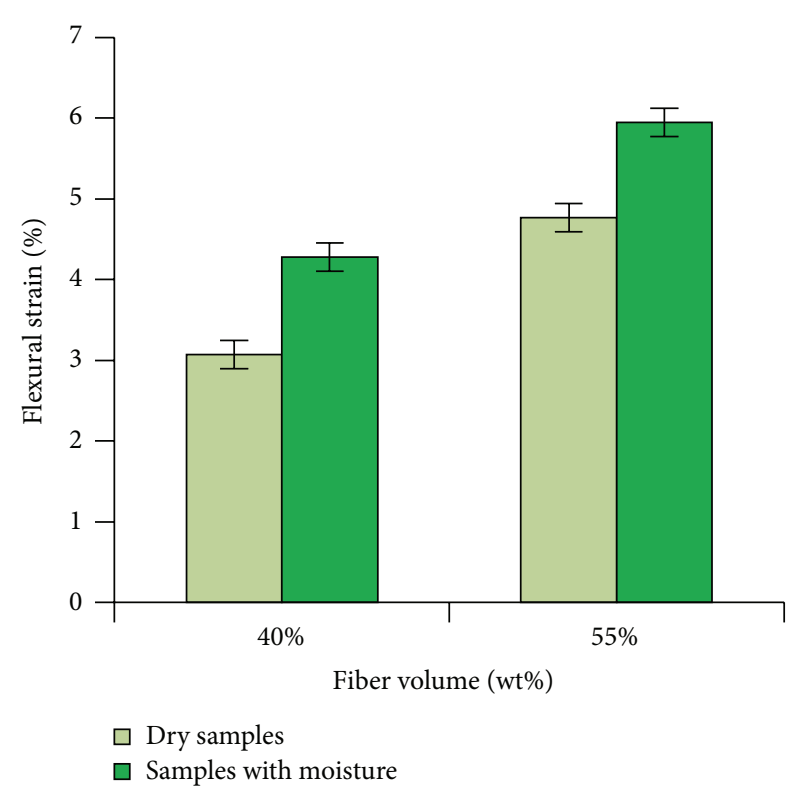

FIGURE 10: Flexural strain versus fibre volume.

Tensile modulus as being dependent on the fibre property in a composite material can be affected as a result of water absorption, whereas the tensile strength of the composite is more sensitive to fibre-matrix interface region properties.

Water absorption does not affect in negative way the flexural modulus. The effect of water absorption is different depending on the fibre volume fraction. Flexural modulus of $40 \mathrm{wt} \%$ fibre content wet specimens increases $11 \%$ compared to dry samples. However, flexural modulus decreases in specimens with higher fibre content, hence higher water content. The flexural modulus of $55 \mathrm{wt} \%$ fibre wet samples decreases by $30 \%$ compared to dry samples. It is possible to assume the effect of the water absorption on the fibre and its effect on the modulus to be less critical for flexural failure than in tensile failure mode.

\section{Conclusions}

This study showed that RTM process could be used to produce high performance natural fibre composites with flax fibre fabric and bioepoxy matrix. This process is an environmental friendly alternative to the use of petroleum-based synthetic fibers and resins. The effect of water absorption on the mechanical properties of flax reinforced bioepoxy composites has been studied by the immersion of the samples in water at room temperature. It shows that water absorption increases with an increase in fibre weight fraction due to a higher cellulose content. At room temperature, it was found that composites follow water absorption Fickian behavior. The diffusion coefficient values obtained in the order of $10^{-6} \mathrm{~mm}^{2} / \mathrm{s}$ are in agreement with the range of values reported, for other natural fibre reinforced composites. It can be concluded that the results suggest that swelling of flax fibers in the composite material as a result of water absorption can have positive effects on mechanical properties. Tensile strength of all water immersed studied specimens is higher compared to the dry samples due to a stronger interfacial bonding between the fiber and the matrix. Flexural properties decrease as water absorption content increases. Tensile modulus was found to decrease with water absorption as a sensitive property of the fibre. Flexural modulus decreases in higher fibre content specimens after water absorption. This flax fibre composites show their potential use in outdoor applications due to the exposure to water absorption not affecting negatively their mechanical properties.

\section{Conflict of Interests}

The authors declare that there is no conflict of interests regarding the publication of this paper.

\section{Acknowledgment}

This research is supported by the Spanish Ministerio de Ciencia e Innovación, Projects PAID-05-11, DPI 2010-20333, and DPI 2013-44903-R-AR. 


\section{References}

[1] C. Baillie, Ed., Green Composites. Polymer Composites and Environment, Woodhead Publishing Limited, Cambridge, UK, 2004.

[2] A. N. Netravali, X. Huang, and K. Mizuta, "Advanced 'green' composites," Advanced Composite Materials, vol. 16, no. 4, pp. 269-282, 2007.

[3] F. P. La Mantia and M. Morreale, "Green composites: a brief review," Composites Part A: Applied Science and Manufacturing, vol. 42, no. 6, pp. 579-588, 2011.

[4] D. N. Saheb and J. P. Jog, "Natural fiber polymer composites: a review," Advances in Polymer Technology, vol. 18, no. 4, pp. 351363, 1999.

[5] P. Wambua, J. Ivens, and I. Verpoest, "Natural fibres: can they replace glass in fibre reinforced plastics?" Composites Science and Technology, vol. 63, no. 9, pp. 1259-1264, 2003.

[6] J. Summerscales, N. P. J. Dissanayake, A. S. Virk, and W. Hall, "A review of bast fibres and their composites. Part 1. Fibres as reinforcements," Composites Part A: Applied Science and Manufacturing, vol. 41, no. 10, pp. 1329-1335, 2010.

[7] J. Summerscales, N. Dissanayake, A. Virk, and W. Hall, "A review of bast fibres and their composites. Part 2-composites," Composites Part A: Applied Science and Manufacturing, vol. 41, no. 10, pp. 1336-1344, 2010.

[8] M. Karus and M. Kaup, "Natural fibres in the European automotive industry," Journal of Industrial Hemp, vol. 7, no. 1, pp. 119-131, 2002.

[9] D. Puglia, J. Biagiotti, and J. M. Kenny, "A review on natural fibre-based composites-part II: application of natural reinforcements in composite materials for automotive industry," Journal of Natural Fibers, vol. 1, no. 3, pp. 23-65, 2004.

[10] N. Uddin and R. R. Kalyankar, "Manufacturing and structural feasibility of natural fiber reinforced polymeric structural insulated panels for panelized construction," International Journal of Polymer Science, vol. 2011, Article ID 963549, 7 pages, 2011.

[11] Y. Xie, C. A. S. Hill, Z. Xiao, H. Militz, and C. Mai, "Silane coupling agents used for natural fiber/polymer composites: a review," Composites Part A: Applied Science and Manufacturing, vol. 41, no. 7, pp. 806-819, 2010.

[12] M. M. Kabir, H. Wang, K. T. Lau, and F. Cardona, "Chemical treatments on plant-based natural fibre reinforced polymer composites: an overview," Composites Part B: Engineering, vol. 43, no. 7, pp. 2883-2892, 2012.

[13] H. N. Dhakal, Z. Y. Zhang, and M. O. W. Richardson, "Effect of water absorption on the mechanical properties of hemp fibre reinforced unsaturated polyester composites," Composites Science and Technology, vol. 67, no. 7-8, pp. 1674-1683, 2007.

[14] H. Alamri and I. M. Low, "Mechanical properties and water absorption behaviour of recycled cellulose fibre reinforced epoxy composites," Polymer Testing, vol. 31, no. 5, pp. 620-628, 2012.

[15] E. Osman, A. Vakhguelt, I. Sbarski, and S. Mutasher, "Water absorption behavior and its effect on the mechanical properties of kenaf natural fiber unsaturated polyester composites," in Proceedings of the 18th International Conference on Composites Materials (ICCM '11), August 2011.

[16] A. C. Karmaker, "Effect of water absorption on dimensional stability and impact energy of jute fibre reinforced polypropylene," Journal of Materials Science Letters, vol. 16, no. 6, pp. 462-464, 1997.
[17] A. Espert, F. Vilaplana, and S. Karlsson, "Comparison of water absorption in natural cellulosic fibres from wood and one-year crops in polypropylene composites and its influence on their mechanical properties," Composites Part A: Applied Science and Manufacturing, vol. 35, no. 11, pp. 1267-1276, 2004.

[18] S. H. Ahmad, N. N. Bonnia, I. Zainol et al., "Polyester-Kenaf composites: effects of alkali fiber treatment and toughening of matrix using liquid natural rubber," Journal of Composite Materials, vol. 45, no. 2, pp. 203-217, 2011.

[19] T. A. Collings, "Moisture absorption-Fickian diffusion kinetics and moisture profiles," in Handbook of Polymer Fibre Composites, F. R. Jones, Ed., pp. 366-371, Longman Scientific and Technical, Essex, UK, 1994.

[20] C.-H. Shen and G. S. Springer, "Moisture absorption and desorption of composite materials," Journal of Composite Materials, vol. 10, no. 1, pp. 2-20, 1976.

[21] J. Holbery and D. Houston, "Natural-fiber-reinforced polymer composites in automotive applications," JOM, vol. 58, no. 11, pp. 80-86, 2006.

[22] G. Francucci and E. Rodriguez, "Processing of plant fiber composites by liquid molding techniques: an overview," Polymer Composites, 2014.

[23] UNE-EN ISO 62: 2008, Plastics. Determination of water absorption.

[24] W. Wang, M. Sain, and P. A. Cooper, "Study of moisture absorption in natural fiber plastic composites," Composites Science and Technology, vol. 66, no. 3-4, pp. 379-386, 2006.

[25] UNE-EN ISO 527-4:1997, Plastics. Determination of tensile properties, Part 4: Test conditions for isotropic and orthotropic fibre-reinforced plastic composites.

[26] ISO, "Fibre-reinforced plastic composites. Determination of flexural properties," UNE-EN ISO 14125:1999, 1999.

[27] K. Charlet, J. P. Jernot, M. Gomina, J. Bréard, C. Morvan, and C. Baley, "Influence of an Agatha flax fibre location in a stem on its mechanical, chemical and morphological properties," Composites Science and Technology, vol. 69, no. 9, pp. 1399-1403, 2009.

[28] F. Destaing, J.-P. Jernot, P. Jouannot-Chesney, M. Gomina, and J. Bréard, "Comparison of morphological and mechanical properties of seven varieties of flax fibres," in Proceedings of the 18th International Conference on Composites Materials (ICCM '11), August 2011.

[29] A. Bismarck, I. Aranberri-Askargorta, J. Springer et al., "Surface characterization of flax, hemp and cellulose fibers; surface properties and the water uptake behavior," Polymer Composites, vol. 23, no. 5, pp. 872-894, 2002.

[30] G. Marom, "The role of water transport in composite materials," in Polymer Permeability, J. Comyn, Ed., chapter 9, Elsevier Applied Science, 1985.

[31] A. C. Karmaker, A. Hoffmann, and G. Hinrichsen, "Influence of water uptake on the mechanical properties of jute fiberreinforced polypropylene," Journal of Applied Polymer Science, vol. 54, no. 12, pp. 1803-1807, 1994.

[32] C. S. Nevin and B. F. Moser, "Vinyl oil monomers. I. Vicinal methacryloxy-hydroxy soy oils," Journal of Applied Polymer Science, vol. 7, no. 5, pp. 1853-1866, 1963.

[33] H. Miyagawa, A. Mohanty, M. Misra, and L. T. Drzal, “Thermophysical and impact properties of epoxy containing epoxidized linseed oil, 2: amine-cured epoxy," Macromolecular Materials and Engineering, vol. 289, pp. 636-641, 2004. 
[34] F.-L. Jin and S.-J. Park, "Thermomechanical behavior of epoxy resins modified with epoxidized vegetable oils," Polymer International, vol. 57, no. 4, pp. 577-583, 2008.

[35] J. Zhu, K. Chandrashekhara, V. Flanigan, and S. Kapila, "Curing and mechanical characterization of a soy-based epoxy resin system," Journal of Applied Polymer Science, vol. 91, no. 6, pp. 3513-3518, 2004.

[36] B. Singh, M. Gupta, and A. Verma, "The durability of jute fibre-reinforced phenolic composites," Composites Science and Technology, vol. 60, no. 4, pp. 581-589, 2000.

[37] B. A. Acha, N. E. Marcovich, and M. M. Reboredo, "Physical and mechanical characterization of jute fabric composites," Journal of Applied Polymer Science, vol. 98, no. 2, pp. 639-650, 2005.

[38] J. Biagiotti, D. Puglia, and J. M. Kenny, "A review on natural fibre-based composites-part I. Structure, processing and properties of vegetable fibres," Journal of Natural Fibers, vol. 1, no. 2, pp. 37-68, 2004.

[39] P. V. Joseph, M. S. Rabello, L. H. C. Mattoso, K. Joseph, and S. Thomas, "Environmental effects on the degradation behaviour of sisal fibre reinforced polypropylene composites," Composites Science and Technology, vol. 62, no. 10-11, pp. 1357-1372, 2002.

[40] A. Stamboulis, C. A. Baillie, and T. Peijs, "Effects of environmental conditions on mechanical and physical properties of flax fibers," Composites Part A: Applied Science and Manufacturing, vol. 32, no. 8, pp. 1105-1115, 2001. 

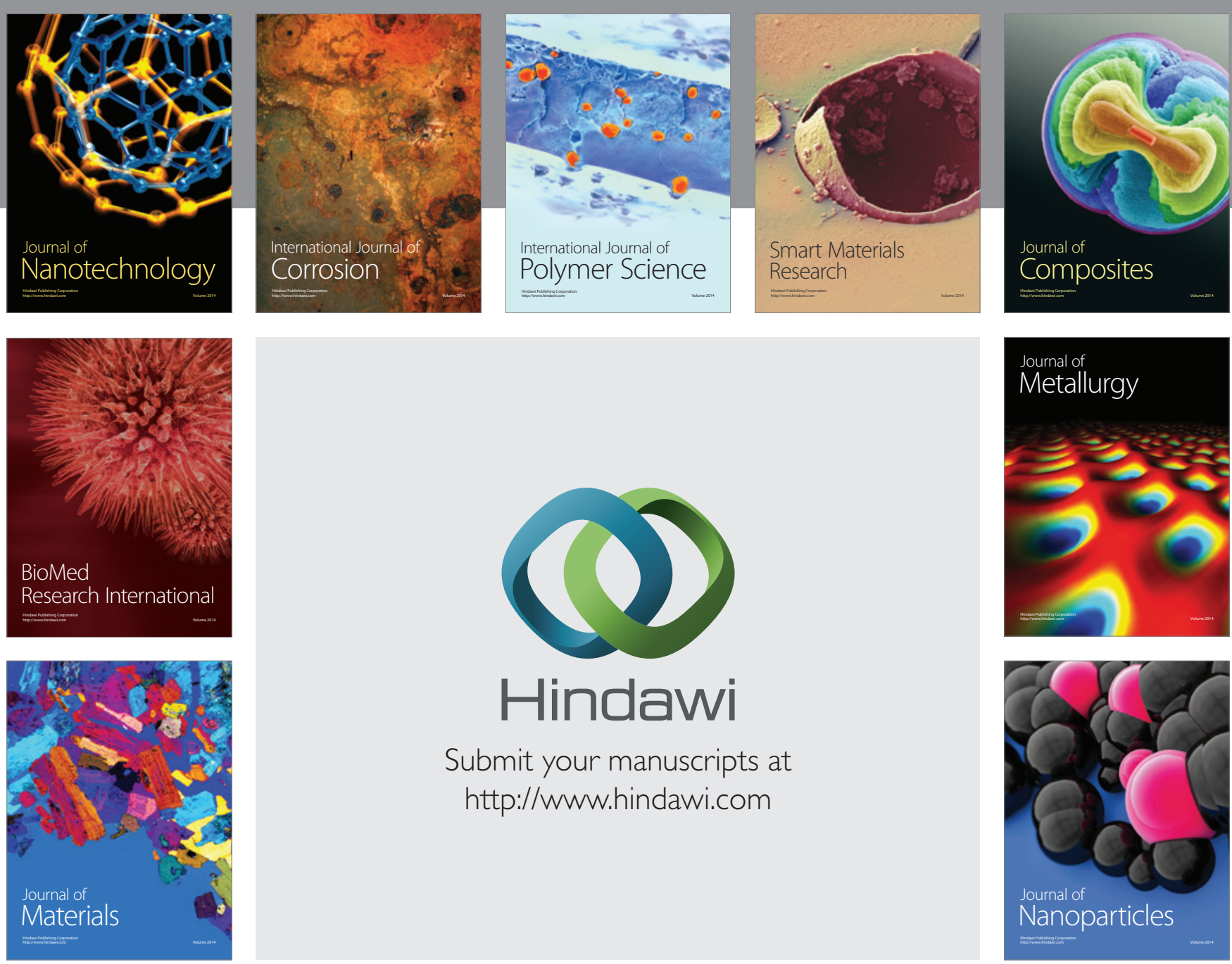

Submit your manuscripts at http://www.hindawi.com
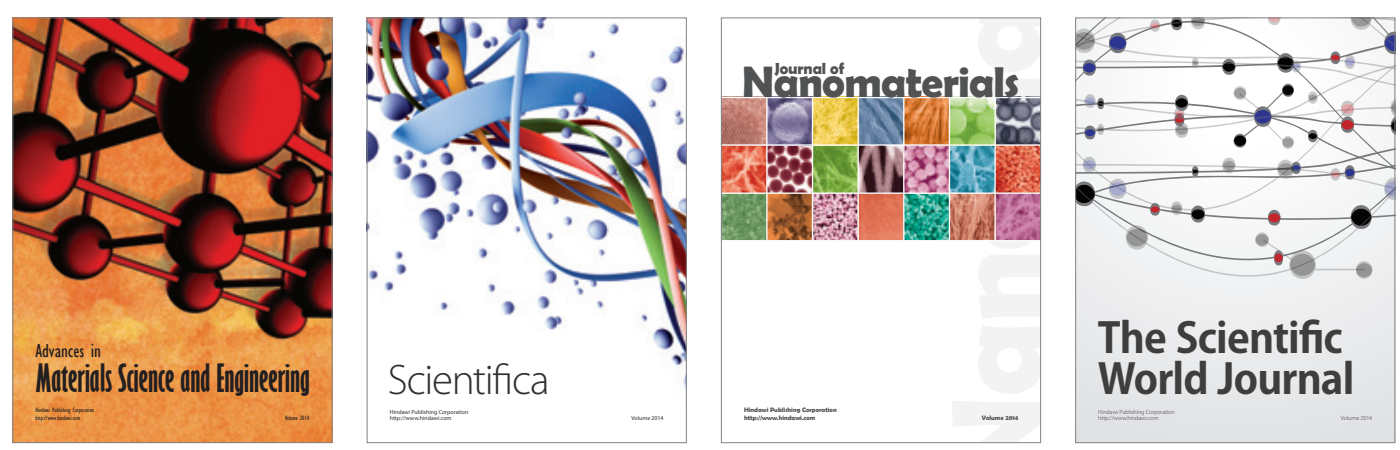

\section{The Scientific World Journal}
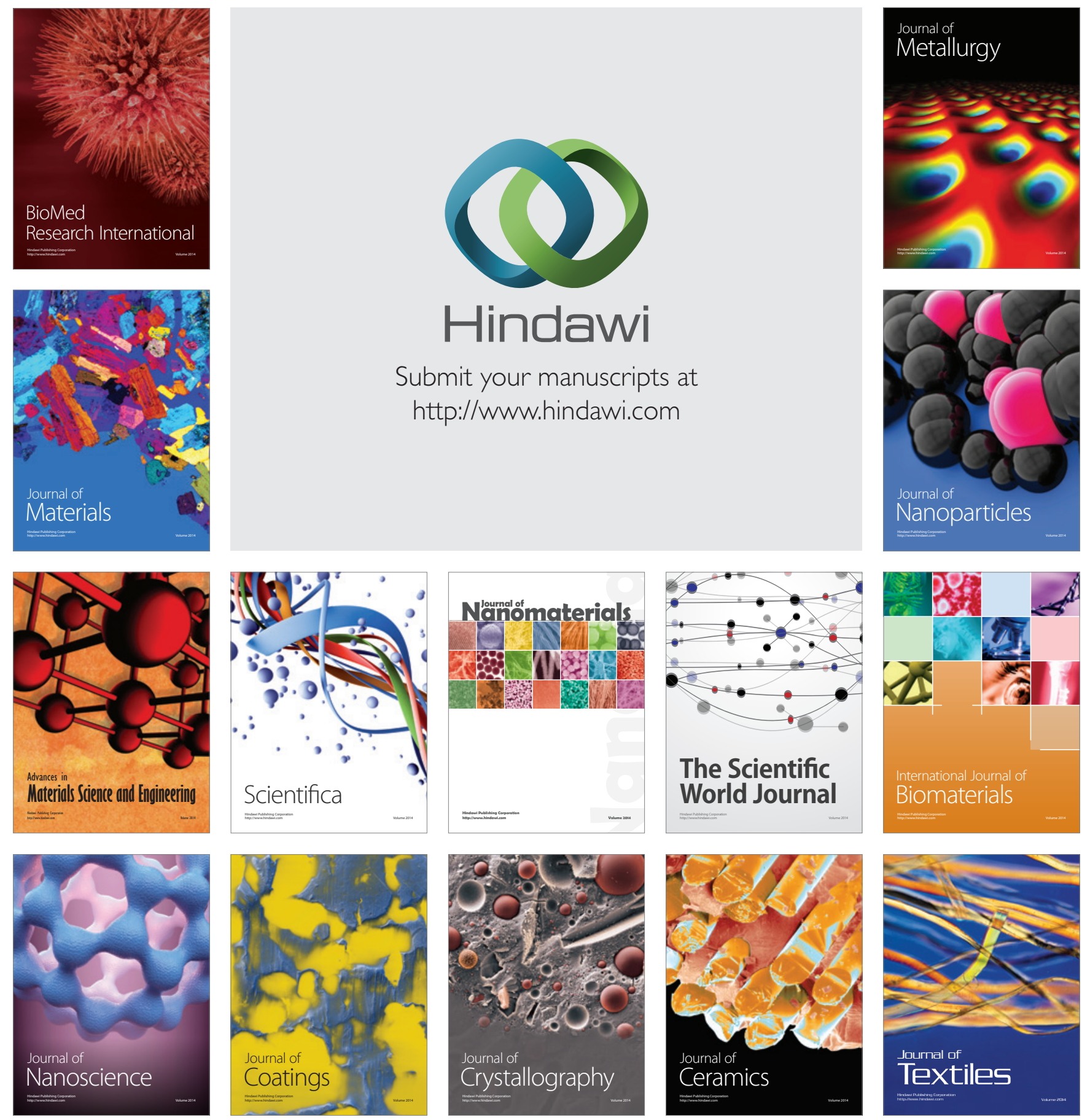